\title{
Analysis of Consumer Data in Diff's Reflexology with Tableau Method
}

\author{
Desi Andriani $^{1}$, Kristina Sisilia ${ }^{2}$ \\ Program Studi S1 Administrasi Bisnis, Fakultas Komunikasi dan Bisnis, Universitas Telkom; \\ ${ }^{1}$ Email address: andriani.desi10@gmail.com; ${ }^{2}$ Email address: kristina@telkomuniversity.ac.id
}

\begin{abstract}
Data management is essential in a company even though it has not an easy process. Diff's Reflexology still records data on consumer data manually and already has data records of each patient that has been treated with various existing treatments. Diff's Reflexology still has problems in terms of effectiveness and efficiency because it still records it manually. The lack of efficacy is indicated by the amount of consumer data that has been lost since the first Diff's Reflexology was established. This research aims to produce useful information so that Diff's Reflexology can increase its effectiveness and efficiency. Data analysis in this study was carried out using the Tableau application, and the research method used was a qualitative research method with a descriptive approach. The results showed that in the last three quarters in 2019, the type of Massage treatment was the highest type of treatment for both male and female consumers. The number of male consumers in Diff's Reflexology was more per month compared to female consumers who are in the fourth quarter of 2019 has 624 male consumers and 366 female consumers. It was found that the productivity of the therapists was different from both male and female therapists, and massage treatment was the highest gross income source with a total of 65 million rupiahs for three quarters.
\end{abstract}

Keywords: data analysis, preferences, Diff's Reflexology, Tableau.

This is an open access article under the CC-BY-NC license.

\section{INTRODUCTION}

The rapid development of information technology has now entered various sectors, including the health service sector. Data management in a company has been greatly assisted and facilitated by the presence of technology and information. Information technology can process data, process data into various details, and can also store more data than the manual method. Besides, due to the rapid development of information, technology also allows data to be sent easily and quickly. Data processing and information retrieval that will make it easier for decision making in a company and will be very profitable and beneficial for the company.

Rud Olivia (2009) defines Business Intelligence (BI) as a variety of tools and techniques to transform raw data into useful and meaningful information to analyze the business, handling large amounts of unstructured data that helps identify, develop, and create new business strategy 
opportunities. In the health service sector, there are many data related to patients. Still, these data will not be useful if there is no proper management and maximum utilization. One of the data contained in Diff's Reflexology is a monthly consumer treatment recap data. However, these data cannot be utilized maximally because they have not utilized information technology and the use of tools that can help produce information from available data. Business Intelligence is useful for solving data processing problems so that it becomes information.

In this study, the benefits of using Business Intelligence (BI) for health service such as Diff's Reflexology are for processing consumer preference data for available treatments, such as knowing how treatment preference trends each month by using one of the business intelligence software that easy to use for data visualization, data analysis, and reporting, the Tableau application. The results of this research analysis are expected to produce information that helps Diff's Reflexology in making the right decision.

\section{LITERATURE REVIEW}

\section{a. Theory of Reflexology}

Reflexology is the provision of energy put into the body through massage to facilitate blood circulation, flexing muscles, increasing endurance, relaxation, increasing the strength of the mind and body, stabilizing emotions, improving sleep quality, restructuring bones, tissues, and organs, healing new and old injuries, increasing concentration and memory, and increasing self-confidence and harmony (Jones, Thompson, Irvine, \& Leslie, 2011).

\section{b. Theory of Consumer Preferences}

Consumer preferences are choices or interests of individuals to express the likes or dislikes of a product. Based on this statement, each consumer has the right to evaluate the goods and services to be purchased. In economic studies, there are four principles of rational choice (Arif, 2010: 110), namely the Principle of Completeness, in which everyone can determine the preferred situation between two conditions. The second principle of Transitivity explains the consistency of a person in deciding his choice if faced with several alternative product choices. Furthermore, the Sustainability principle explains that if someone states "preferring product $\mathrm{X}$ over product $\mathrm{Y}$," then every situation approaching product $\mathrm{X}$ will be preferred over product $\mathrm{Y}$. So consumers will be consistent in choosing the product they want to consume. The More is The Better Principle, which says that if a person consumes more products, then the amount of satisfaction will increase so that consumers tend always to increase their consumption to get a sense of achievement.

\section{c. Theory of Business Intelligence}

Business Intelligence is a process starting from taking data, analyzing data, and presenting the results, which are the essence of data that is the basis for business actions that enable management to make decisions in daily business activities (Stackowiak, 2007). Based on this definition, business intelligence can be interpreted as a system that functions in processing operational, transactional, and other data in a company or organization so that it becomes valuable information. Business Intelligence is used to analyze data in the past, then the knowledge obtained is used to assist companies in making decisions and organizational planning. Business Intelligence can be categorized into three main categories (Turban et al., 2011):

1. Information and knowledge discovery acts as a means of observation of existing information to predict what will happen in the future to find opportunities.

2. Decision support and intelligent systems (DDS), managers, and executives need a BI system to support its performance, especially in decision making or at the strategic stage. 
3. Visualization is a technology that supports the display or translation of data from Business Intelligence such as digital images, geographic information systems, graphical user interfaces, multidimensions, tables and graphs, virtual reality, three-dimensional presentations, and animations.

The benefits and advantages that can be obtained in implementing business intelligence in a company are as follows:

1. Improve Management Processes

The benefits that companies can feel in implementing business intelligence are that they can improve management processes such as planning, controlling, and monitoring so that the company can increase revenue. Controlling and monitoring are driven by the existence of key performance indicators (KPI) in the development of business intelligence. KPI can show the achievement of an organization/company that can facilitate top-level management in decision making and determine the steps taken afterward.

2. Improve Operational Processes

The next benefit is that it can improve operational processes such as the process of ordering customers, purchasing, and accounts payable processes. Companies can find productive and profitable market shares, so they can survive and expand business and marketing networks. It can create strategies that benefit the company.

3. Automation of Decision Making

Automated Decision System (ADS) is an approach that can help in making decisions that are useful in specifying management problems that often recur, such as determining the price decision of an item for the sale of a company's products (Turban, Sharda, Delen, \& King, 2011). Business intelligence is useful to assist companies in making decisions with the use of information, where processed data sources can provide information in the form of new perspectives related to decision making.

\section{d. Research Framework}

A thinking framework is used as an instruction in a study to stay focused on the problem being examined, namely Analysis of Consumer Data in Diff's Reflexology with the Tableau Method. The author wants to analyze how the trend of treatment preferences in Diff's Reflexology in the last three quarters to detect resource usage based on their efficient and effective terms.

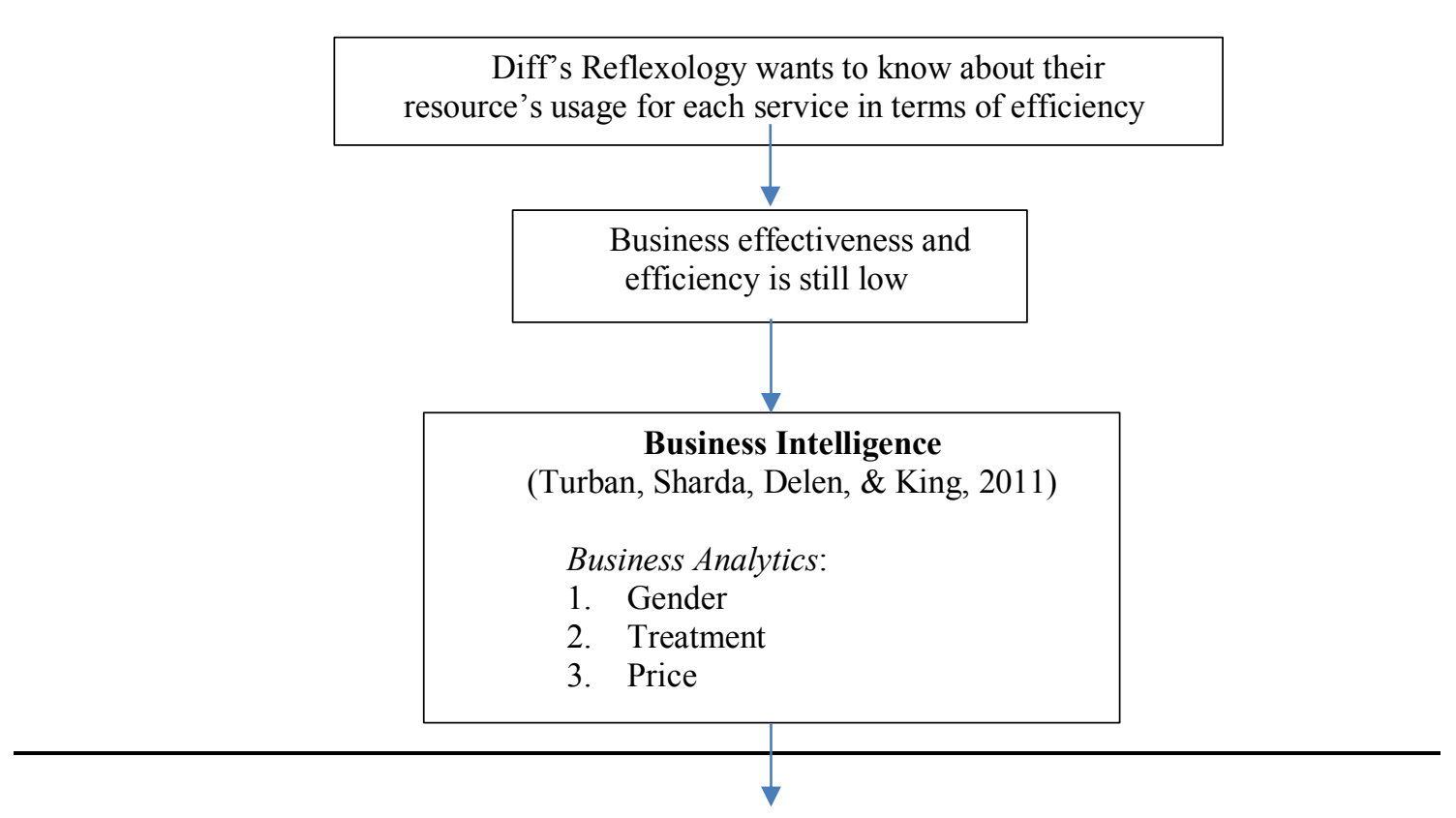




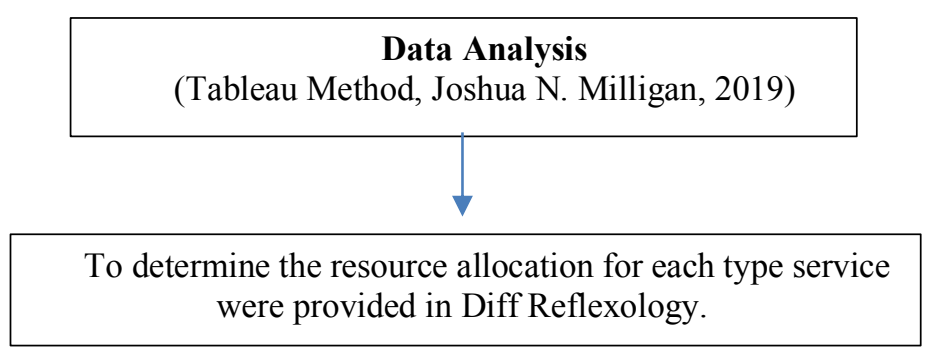

Figure 1 Research Framework

(Source: Reasercher's Data, 2019)

\section{RESEARCH METHODOLOGY}

The research methodology used by researchers is qualitative. According to Bogdan \& Taylor in Moleong (2007: 4), qualitative methods is a research procedure that produces descriptive data in the form of written or oral words from people, and observable behavior. Then this research uses a descriptive approach. According to Nazir (2005: 54-55), a descriptive approach studies the problems in society, the procedures that apply in community, certain situations, including about relationships, activities, attitudes, views, and processes the ongoing process, and the effects of a phenomenon. Data collected in the form of words, pictures, and not numbers.

In qualitative research, research subjects can be things or people. Therefore, the issues in this study are Diff's Reflexology and people who provide information about the data desired by researchers and related to the research being carried out. The subject in this study was the owner of Reflexology Diff, Mr. Dudu Hafidz, as well as two front office staff at Ref's Reflexology, Linda Nurfaidah, and Fitri Agustin Nurnovianti. Then the expert informant in the analysis of data by the Tableau method is Mrs. Kristina Sisilia. The data collected in this study uses the techniques of documentation, observation, and interviews as a form of primary data. Besides, there are also secondary data obtained from books, national and international journals, thesis, or previous research that has a relationship with this research. The documents that the researchers chose in this study are documents related to recording consumer data in Diff's Reflexology.

Data analysis in this study was carried out using a tool in the form of a Tableau application. Tableau is an easy-to-use business intelligence software for creating data visualization, data analysis, and reporting. How to use Tableau is reasonably easy because it uses a drag and drop system.

\section{FINDING AND DISCUSSION}

In this section, we will explain the results of research from processing consumer data. There are results in the form of trends in consumer preferences treatment in Diff's Reflexology in the last three quarters, comparison of the number of consumers by gender, comparison of therapist productivity, and comparison of the number of treatments based on price.

\section{a. Data processing}

The data processed in this study are consumer data in Diff's Reflexology from April to December 2019. Consumer data is obtained directly from Diff's Reflexology in the form of manual recording data in notebooks. Then converted into Excel Data consisting of 2416 rows and 8 Columns are categorized by date, number, consumer name, gender, type of treatment, duration, therapist's name, and price. The data will then be analyzed and visualized. 


\section{b. Data Execution Process}

Data that is still in the form of manual recording in books from April to December 2019 will be changed to Excel Data. So, the data preparation here is in the way of a Microsoft Excel data file and can be entered into Tableau with the "to a file" category because the data is in the form of a static file that is final and can be analyzed. In this study, the columns needed to visualize the data are date, number, consumer name, gender, type of treatment, duration, therapist's name, and price. These columns will later be paired with each other to produce the desired data visualization. Consumer data from April to December 2019 is integrated into one worksheet in Microsoft Excel because consumer data each month has the same data type.

Loading data that is connecting data by dragging data files that have been prepared into Tableau. The data will later become a data source that displays the data that will be used for processing or visualization then. The information that has been presented in the data source can also automatically show what types of data were in the previous Excel data worksheet. As in the date column, Tableau automatically categorizes the column into a Date data type, the number column is classified as the Number data type, and so on by adjusting the contents of each column.

Processing and data analysis. After the data is loaded into Tableau and seen in the data source, the next step is processing or visualizing the information on the Sheetl page. The left side of the worksheet displays dimensions which usually contain certain data types such as gender, duration, name, and type of treatment. While the measures generally provide data in the form of numbers such as prices and amounts. Data visualization is then analyzed based on each variable that wants to be known to be able to produce information that occurred in the past and becomes a reference for making decisions in the future.

\section{c. Data Process Results}

After the data process is done, there is a result which is comparison information of the type of treatment that is the consumer's preference in the last three quarters in Diff's Reflexology. A comparison of the number of consumers based on gender, comparison of therapist productivity, and comparison of the number of treatments based on price.

\section{Comparison of selected treatment types per quarter}

In the last three quarters, we can find comparative information on the types of medications that are the preferences of male and female consumers in Diff's Reflexology. The data process is carried out based on the date, gender of the consumer, and the type of treatment chosen then calculated per quarter. The kind of treatment that many consumers want is massage and Matsu, and this shows that there is a consumer preference for a product. Diff's Reflexology addresses this as a natural thing because every consumer has their own choices and interests in a product. However, from the results of data visualization in Figure 2, each type of treatment that is above 50 is the type of therapy that contributes a lot to income because it is considered to be a right and visible remedy in the business to be more focused. 
Proceeding on Business, Economy, Management and Social Studies towards Sustainable Economy (BEMSS)),

$$
\text { Vol. } 1 \text { (1), 8-16 }
$$

Analysis of Consumer Data in Diff's Reflexology with Tableau Method

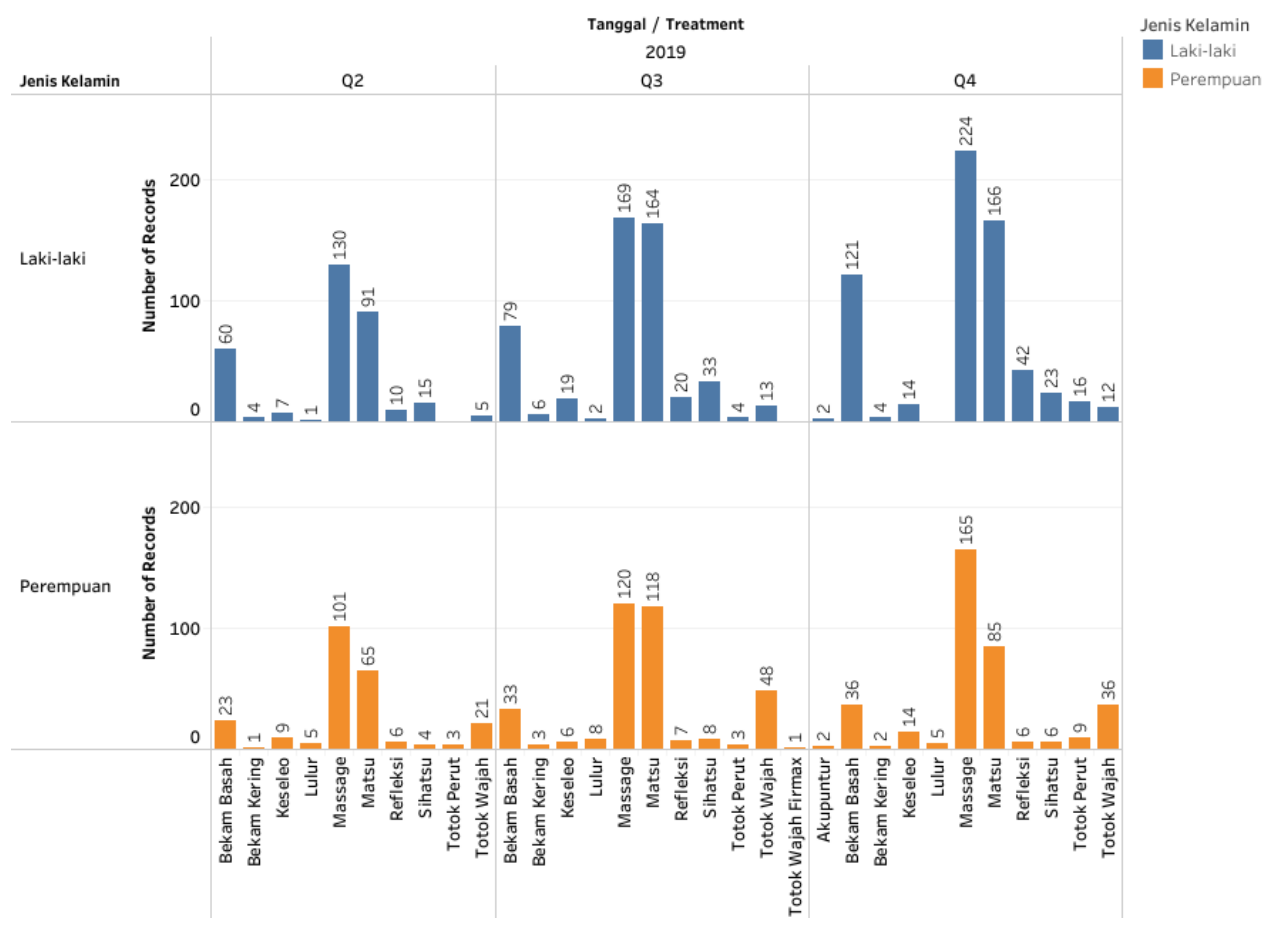

Figure 2 Comparison of selected treatment types per quarter Source: Data processed by Tableau Method, 2020

\section{Comparison of male and female consumers per quarter}

The number of male consumers in Diff's Reflexology is more per month compared to female consumers, although both experience ups and downs. A comparison of the number of consumers in Diff's Reflexology must be adjusted to the number of therapists available. At present, it is known that there are 11 active female therapists and 10 for male therapists. If compared with the comparison of the number of consumers, the number of male therapists should be more than the number of female therapists to be able to adjust to the existing demand.

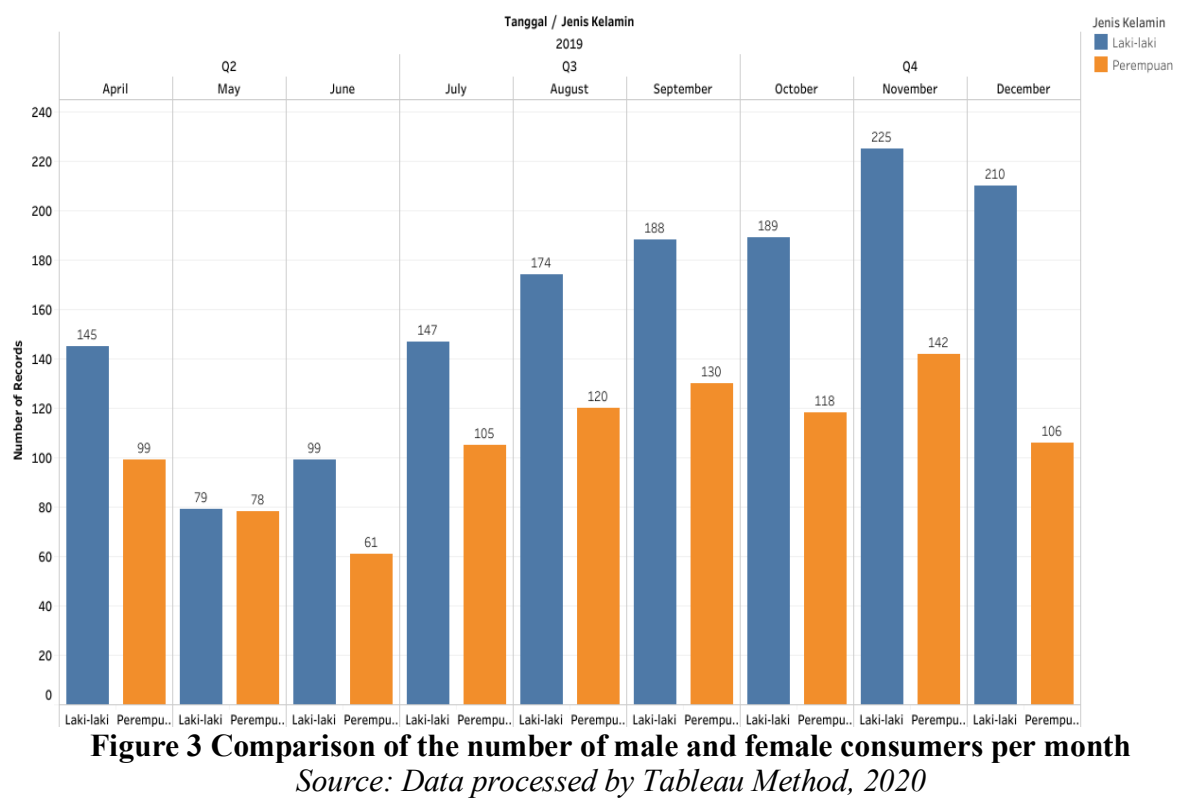




\section{Comparison of therapist productivity per quarter}

The results of data visualization of the number of male and female consumers can then provide an overview of the number of therapist productivity comparisons in Diff's Reflexology. By including therapist variables in the graph of the number of consumers by gender so that it can be seen the contrast of the number of each therapist in serving consumers per quarter. Comparison of the productivity of female and male therapists in Figure 4 and Figure 5, there is information that some therapists have considerable differences compared to other therapists in terms of total productivity. The reason for this vast difference is the number of attendees from each different therapist, their expertise, and consumer demand.

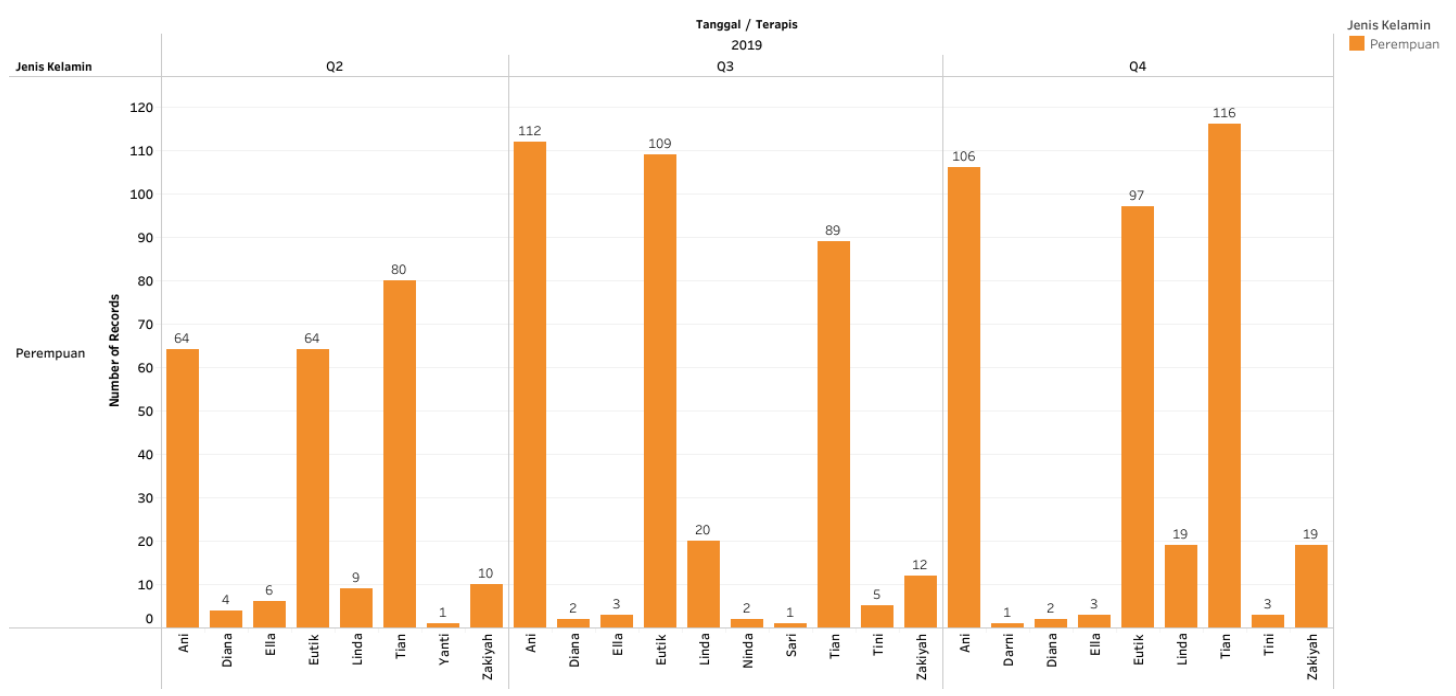

Figure 4 Comparison of female therapist productivity per quarter Source: Data processed by Tableau Method, 2020

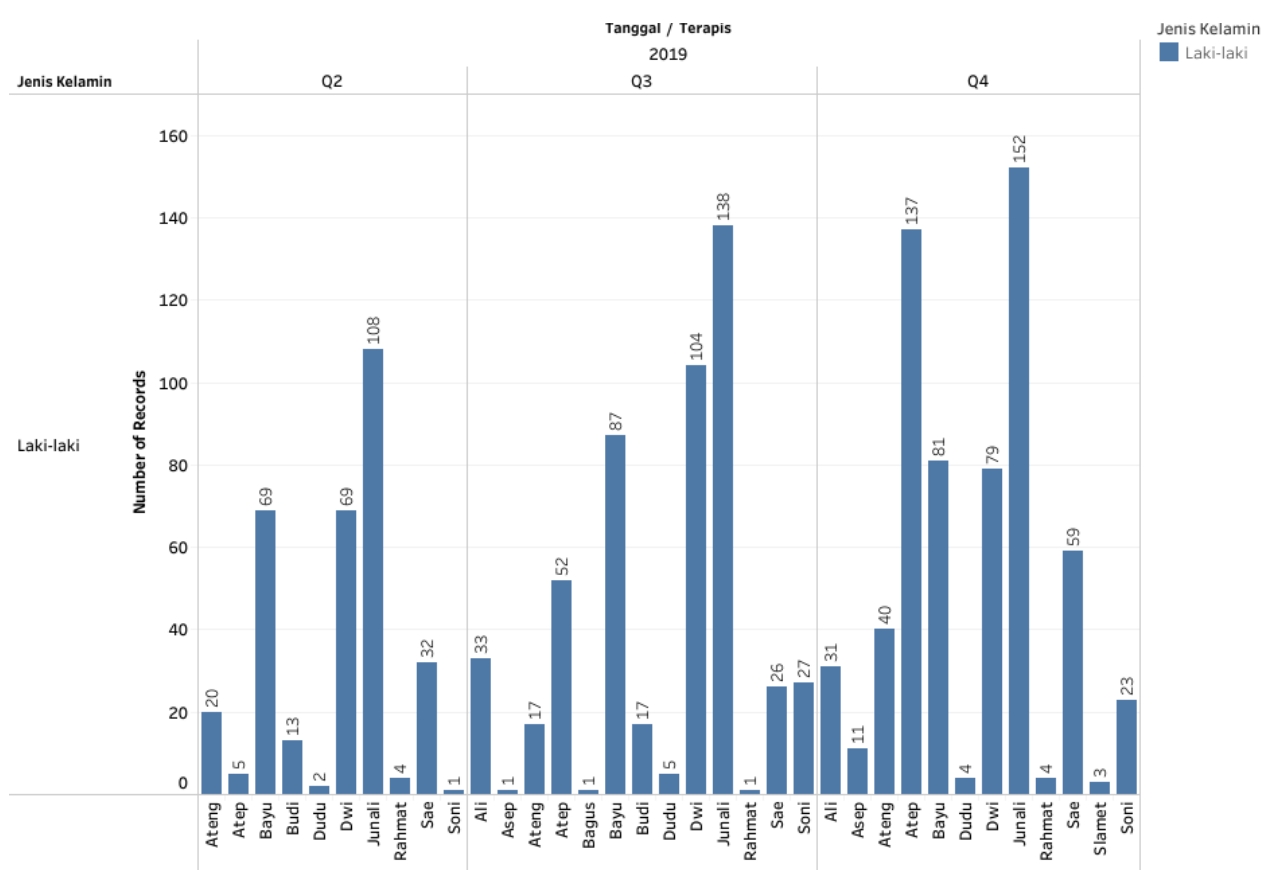

Figure 5 Comparison of male therapist productivity per quarter Source: Data processed by Tableau Method, 2020 


\section{Revenue per quarter}

Each type of treatment has a varying price that is adjusted based on the length of time requested by the consumer. Based on Figure 6, it can be seen that massage and Matsu treatments are the most significant source of income compared to other treatments. Diff's Reflexology consumers mostly choose massage and Matsu treatments because the procedure does indeed provide care for the whole body so that the price offered will feel like the benefits will be obtained.

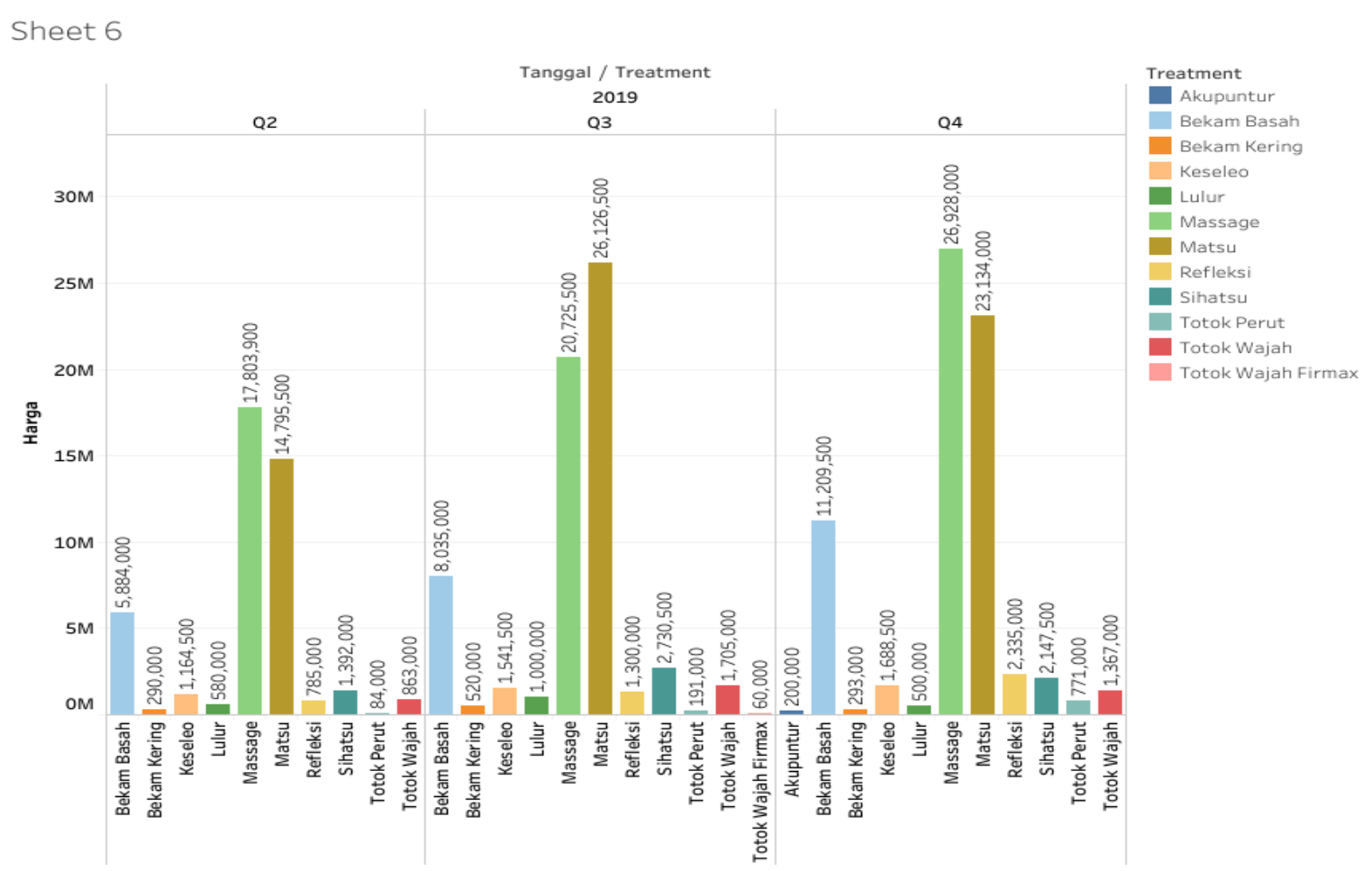

Fig. 6 Comparison of gross maintenance revenue per quarter

Source: Data processed by Tableau Method, 2020

\section{CONCLUSION AND FURTHER RESEARCH}

Based on the results of the research analysis and discussion that has been described regarding the interpretation of consumer data in Diff's Reflexology with the Tableau method, the following conclusions can be obtained:

1. The type of treatment chosen by consumers

In the last three quarters, we can find comparative information on the types of surgeries that are the preferences of male and female consumers in Diff's Reflexology. Quarterly, the type of Massage treatment is the highest type of treatment for both male and female consumers compared to others and continues to increase. As for the second type of treatment, the choice of many consumers is Matsu.

2. The number of male and female consumers

The number of male consumers in Diff's Reflexology is more per month compared to female consumers, although both experience ups and downs. Data on the number of consumers by gender per quarter obtained information that consumers with the highest gender of men and women occurred in the 4th quarter of October to December in 2019 with 624 male customers and 366 female consumers. 
3. Total therapist productivity

In the last three quarters, we can find out information on the productivity of therapists who are different, both female and male therapists in each quarter. Some therapists increase every quarter, and some fluctuate. Besides, it is also known that some therapists only replace other therapists because they only work one to three times over three quarters.

4. Revenue from treatment

Total gross income for each treatment for three quarters can be seen by processing data based on the date, type of treatment, and price chosen. Each type of treatment has a number that varies according to the length of time requested by the consumer. Information obtained from the results of data visualization, namely massage and Matsu treatments, is the most significant source of income compared to other treatments.

\section{REFERENCES}

Akbar, R., Soniawan, A., Dinur, R., Adrian, J., Azim, R., \& Zikri, A. (2017). Implementasi Business Intelligence untuk Menganalisis Data Persalinan Anak di Klinik Ani Padang dengan Menggunakan aplikasi Tableau Public. JOIN | Volume 2 No.1 | Juni 2017, 20-24.

Cahyana, R. J. (2019, Oktober 31). Fungsi dan Peranan Teknologi Informasi (Aplikasi/Software) Bagi Perusahaan. Retrieved from Kompasiana: https://www.kompasiana.com/raffiansyahjc/5656f3cb159373db144f054d/fungsi-danperanan-teknologi-informasi-aplikasisoftware-bagi-perusahaan?page $=$ all

Jones, J., Thompson, P., Irvine, K., \& Leslie, S. J. (2011). Specific Hemodynamic Effects of Reflexology. Department of Nursing \& Midwifery Stirling University, Center for Health Science Old Perth Road, Inverness, IV2 3JH.

Lupiyoadi, R. (2014). Manajemen Pemasaran Jasa. Jakarta: Salemba Empat.

Milligan, J. N. (2019). Learning Tableau 2019: Tools for Business Intelligence, data prep, and visual analytics, 3rd Edition. Birmingham: Packt Publishing.

Moleong, L. J. (2007). Metode Penelitian Kualitatif. Bandung: PT. Remaja Rosdakarya,.

Nazir, M. (2015). Metode Penelitian. Bogor: Ghalia Indonesia.

Rud, O. P. (2009). Business Intelligence Success Factors. Hoboken, N.J: Wiley \& Sons.

Stackowiak. (2007). Oracle Data Warehousing and Business Intelligence Solutions. Indianapolis: Wiley.

Turban, E., Sharda, R., Delen, D., \& King, D. (2011). Business Intelligence A Managerial Approach. New Delhi: Prentice-Hall. 